\title{
Evaluation of photodynamic therapy in adhesion protein expression
}

\author{
CRISTINA PACHECO-SOARES ${ }^{1}$, MAIRA MAFTOU-COSTA ${ }^{2}$, \\ CAROLINA GENÚNCIO DA CUNHA MENEZES COSTA ${ }^{1}$, \\ ANDREZA CRISTINA DE SIQUEIRA SILVA ${ }^{1}$ and KAREN C.M. MORAES ${ }^{3}$
}

${ }^{1}$ Laboratory of Dynamics of Cellular Compartments, University of Vale do Paraiba, Institute for Research and Development, São José dos Campos-SP 12244-000; ${ }^{2}$ Department of Pharmacology, Federal University of São Paulo, São Paulo-SP 04021-001; ${ }^{3}$ University of São Paulo, Institute of Biosciences of Rio Claro, Rio Claro-SP 13506-900, Brazil

Received August 8, 2013; Accepted February 18, 2014

DOI: $10.3892 / 01.2014 .2149$

\begin{abstract}
Photodynamic therapy (PDT) is a treatment modality that has clinical applications in both non-neoplastic and neoplastic diseases. PDT involves a light-sensitive compound (photosensitizer), light and molecular oxygen. This procedure may lead to several different cellular responses, including cell death. Alterations in the attachment of cancer cells to the substratum and to each other are important consequences of photodynamic treatment. PDT may lead to changes in the expression of cellular adhesion structure and cytoskeleton integrity, which are key factors in decreasing tumor metastatic potential. HEp- 2 cells were photosensitized with aluminum phthalocyanine tetrasulfonate and zinc phthalocyanine, and the proteins $\beta 1$-integrin and focal adhesion kinase (FAK) were assayed using fluorescence microscopy. The verification of expression changes in the genes for FAK and $\beta 1$ integrin were performed by reverse transcription-polymerase chain reaction (RT-PCR). The results revealed that HEp-2 cells do not express $\beta$-integrin or FAK $12 \mathrm{~h}$ following PDT. It was concluded that the PDT reduces the adhesive ability of HEp- 2 cells, inhibiting their metastatic potential. The present study aimed to analyze the changes in the expression and organization of cellular adhesion elements and the subsequent metastatic potential of HEp-2 cells following PDT treatment.
\end{abstract}

\section{Introduction}

Photodynamic therapy (PDT) is a treatment modality for various tumors and non-malignant diseases, in which visible light is used to activate a photosensitizer $(1,2)$. The precise

Correspondence to: Dr Cristina Pacheco-Soares, University of Vale do Paraiba, Institute for Research and Development, 2911 Av. Shishima Hifumi, São José dos Campos-SP 12244-000, Brazil E-mail: cpsoares@univap.br

Key words: phthalocyanines, focal adhesion, $\beta 1$-integrin, reverse transcription-polymerase chain reaction, cell culture mechanism of PDT on cells and tissues has not been fully elucidated. However, singlet oxygen generated following exposing the sensitizer to an appropriate light wavelength has been identified as the possible cytotoxic agent responsible for direct tumor cell damage or cell death (3).

Phthalocyanines belong to a second generation photosensitizer and are reported as the most effective drugs for PDT (4). Phthalocyanines constitute a large class of compounds with high extinction coefficients in the red spectral region (630 and $800 \mathrm{~nm}$ ), which have been identified to present excellent tumor-localizing properties and high photosensitizing efficiency (5).

Cellular components are adhered to the extracellular matrix (ECM) and among them are cell adhesion proteins, which allow cell anchorage, survival, proliferation and migration. There are four main cell adhesion protein superfamilies, including integrins, selectins, immunoglobulins and cadherins (6). Integrins are ubiquitous glycoproteins that modulate cell adhesion to the ECM components, including collagen, fibronectin, laminin and vitronectin. These elements form a link between the extracellular environment and the cytoskeleton, through interactions with adaptor proteins that constitute focal adhesion contacts. In particular, integrins participate in the regulation of survival, proliferation, migration and differentiation (6).

It has been established that PDT produces changes in the ECM and to cell adhesion, which are largely dependent on the type of photosensitizer and the treatment doses (7); however, the mechanisms underlying this effect remain elusive. In one study, the cells subjected to PDT, using an hematoporphyrin derivative as a photosensitizing agent, required a longer time to adhere to a plastic substrate and a confluent layer of untreated cells when compared with the control group, suggesting that the damaging effects involve cytoskeletal proteins (8). Furthermore, cytoskeletal reorganization damage following photodynamic treatment has been reported in several other studies $(1,9,10)$, and it has been observed that changes in the capacity of PDT-induced cell adhesion is accompanied by remodeling of actin filaments $(11,12)$.

The present study aimed to investigate the adhesion process of the cell line HEp-2 (human laryngeal carcinoma) 
that have been subjected to PDT with the photosensitizing aluminum phthalocyanine tetrasulfonated $\left(\mathrm{AlPcS}_{4}\right)$ and zinc phthalocyanine $(\mathrm{ZnPc})$.

\section{Materials and methods}

Cell line. The HEp-2 human laryngeal cancer cells, (Adolfo Lutz Institute, São Paulo, Brazil) were cultured as a monolayer of cells in Dulbecco's modified Eagle's medium (DMEM), supplemented with $10 \%$ fetal bovine serum (FBS), penicillin (100 U/ml) and streptomycin $(100 \mathrm{mM} / \mathrm{ml}$; Gibco-BRL, Carlsbad, CA, USA).

Chemicals. ZnPc, violet crystal, human collagen type IV, phalloidin-TRITC, anti-focal adhesion kinase (FAK) and anti- $\beta 1$-integrin monoclonal antibodies were obtained from Sigma Chemical Co. (St.Louis, MO,USA). AlPcS 4 was obtained from Frontier Scientific, Inc., (Logan, UT, USA). Mouse anti-rabbit fluorescein isothiocyanate (FITC)-conjugated and calcein-AM IgG, as well as primers for $\beta 1$-integrin, FAK and $\beta$-actin, were obtained from Invitrogen Life Technologies (Carlsbad, CA, USA).

Photodynamic therapy. The cells were exposed to the photosensitizers AlPcS4 $\left(10 \mu \mathrm{M} \mathrm{ml}^{-1}\right)$ or $\mathrm{ZnPc}\left(10 \mu \mathrm{M} \mathrm{ml}^{-1}\right)$ for $1 \mathrm{~h}$ and were irradiated with an As-Ga-Al diode laser (wavelength, $650 \mathrm{~nm}$; energy density, 4,5 J/ $\mathrm{cm}^{2}$; Bio Wave LLLT Dual-Kondortech, São Carlos-SP, Brazil).

Immunostaining. Tissue culture plates were coated overnight with human collagen type IV $(5 \mu \mathrm{g} /$ well $)$ at room temperature under sterile conditions. The wells were washed with phosphate-buffered saline (PBS; Sigmal Chemical Co.) and non-specific binding sites were blocked with $100 \mu \mathrm{l}$ of $0.2 \%$ bovine serum albumin (BSA; Sigma Chemical Co.) in DMEM (Gibco-BRL) for $90 \mathrm{~min}$ at $37^{\circ} \mathrm{C}$. The wells were seeded with $500 \mu \mathrm{l}$ of the appropriate cell suspension, $10^{5}$ cells $/ \mathrm{ml}$, and incubated at $37^{\circ} \mathrm{C}$ in a humidified $5 \% \mathrm{CO}_{2}$ incubator for $24 \mathrm{~h}$. The attached cells following incubation with AlPcS4 or $\mathrm{ZnPc}$ were irradiated and immediately the groups were separated at the times of 0 and $12 \mathrm{~h}$, and cells were incubated in $4 \%$ paraformaldehyde (Sigma Chemical Co.) in PBS for 15 min at room temperature. Cells were permeabilized with $0.2 \%$ of Triton X-100 (Sigma Chemical Co.) and 4\% paraformaldeyde in PBS for $10 \mathrm{~min}$, and then blocked with $1 \%$ BSA solution in PBS for $30 \mathrm{~min}$. Subsequently, cells were incubated with phalloidin-TRITC (1:100/1 h; Sigma Chemical Co.), mouse anti-human monoclonal antibody against $\beta 1$-integrin $(1: 500 / 1 \mathrm{~h})$ or mouse anti-human monoclonal antibody against FAK (1:500/1 h) (both Sigma Chemical Co.), and then incubated with the rabbit anti-mouse polyclonal secondary antibody conjugated with fluorescein (FITC; 1:1,000/1 h).

Reverse transcription-polymerase chain reaction (RT-PCR). Total cellular RNA was extracted by TRIzol (Invitrogen Life Technologies). Reverse transcription of $1 \mu \mathrm{g}$ RNA was conducted using Taq $\mathrm{Man}^{\circledR}$ reverse transcription reagents (Invitrogen Life Technologies) according to the manufacturer's instructions. Equal amounts of cDNA (1/20 of the reaction volume) were subjected to PCR amplification using the following primers: $\beta 1$-integrin: forward, 5'-GGACAGTGTGTTTGTAGGAAGAGG-3' and reverse, 5'-GCACTGAACAGATTCTTTATGCTC-3'; FAK: forward, 5'-TGCAAGTAAGGAAATACAGTTTGG-3' and reverse, 5'-CCACATACACACACCAAACATCATCCA-3', and were then visualized by ethidium bromide-stained agarose gel (Sigma Chemical Co.) electrophoresis. RT-PCR was performed using standard conditions.

Cell-cell adhesion assay. Following PDT, cells were incubated with calcein-AM $(2 \mu \mathrm{M} / 30 \mathrm{~min})$ and seeded $\left(10^{5}\right.$ cells/well $)$ over a HEp-2 culture in a confluent monolayer in 96-well plates. Cells were incubated at $37^{\circ} \mathrm{C}$ for $2 \mathrm{~h}$. Following this time, the non-adherent calcein-labeled cells were removed for washing with the culture medium. The attached cells were incubated for 12 and $24 \mathrm{~h}$. The number of cells attached was determined at the end of each period using a Leica DMLB fluorescence microscope (Leica Microsystems, Milton Keynes, Buckinghamshire, UK).

Cell-matrix adhesion assay. Cells submitted to treatment following the incubation periods, were seeded at a concentration of $10^{5}$ cells/well in coverslips coated with human collagen type IV and incubated at $37^{\circ} \mathrm{C}$ with DMEM with $2 \% \mathrm{FBS}$ to allow adhesion. Following this period, the non-adherent cells were removed with PBS and fixed with $96 \%$ ethanol for $10 \mathrm{~min}$ at room temperature. The cells were incubated with $0.1 \%$ crystal violet (Sigma Chemical Co.) for $30 \mathrm{~min}$. Excess dye was removed with distilled water and then $300 \mu$ l dimethyl sulfoxide (Sigma Chemical Co.) was added for extraction of the label. The optical density of the plates was read at $570 \mathrm{~nm}$ on a microplate reader (Packard SpectraCount; Packard BioScience Co., Meriden, CT, USA). Each experiment was run in triplicate.

Statistical analyses. The data are presented as the mean \pm standard deviation. All results presented a Gaussian distribution allowing the use of analysis of variance to compare means among the groups. $\mathrm{P}<0.05$ was considered to indicate a statistically significant difference. To conduct the statistical analysis and graphics, GraphPad InStat ${ }^{\circledR}$ and Microcal Origin ${ }^{\circledR} 6.0$ software were used, respectively.

\section{Results}

Effect of PDT on cell morphology. Immunostaining analysis revealed that PDT acted on the actin filaments of the cytoskeleton and the adhesion proteins $\beta 1$-integrin and FAK. A total of $12 \mathrm{~h}$ following PDT, immunostaining analysis observations of the control group revealed a homogeneous distribution of actin filaments with stress fiber characteristics (Fig. 1A). Following PDT, intense retraction in the actin filaments was observed in the $\mathrm{AlPcS}_{4}$ and $\mathrm{ZnPc}$ groups when compared with control group, revealing severe damage that was compromising the cellular morphology and the loss of integrity of the filaments with the disappearance of stress fibers (Fig. 1B and C). This consequently led to damage to the internal organization, mechanical and structural stability of the cells. Cell adhesion features and changes in commitment, adhesive proteins $\beta 1$-integrin and FAK are illustrated in Fig. 2. Immediately following treatment, the 

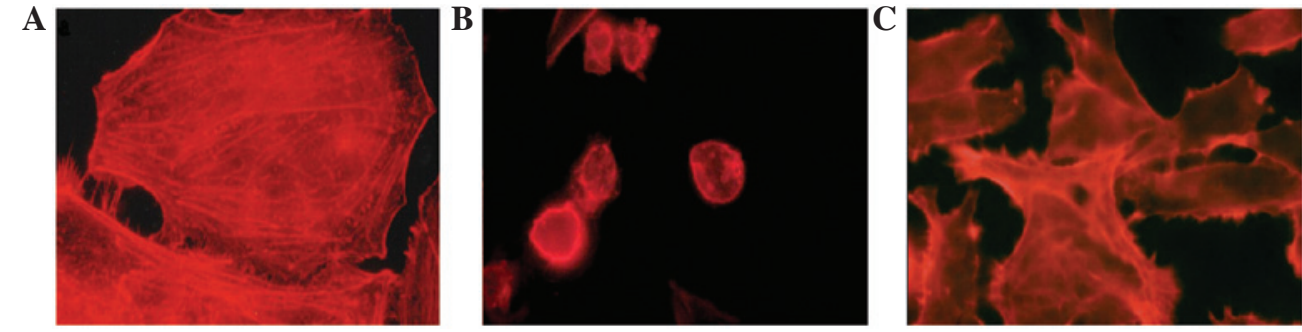

Figure 1. HEp-2 cells labeled with phalloidin-TRITC, $12 \mathrm{~h}$ following PDT. (A) The control group, non-irradiated cells with intact cytoskeleton (arrow); (B) the $\mathrm{AlPcS}_{4} / \mathrm{PDT}$ group, the filaments are concentrated in the cell periphery (arrow), with retraction of the cytoplasm; (C) in the $\mathrm{ZnPc} / \mathrm{PDT}$ group, the disappearance of stress fibers of actin filaments (arrow) was observed. PDT, photodynamic therapy; $\mathrm{AlPcS}_{4}$, aluminum phthalocyanine tetrasulfonated; ZnPc, zinc phthalocyanine.
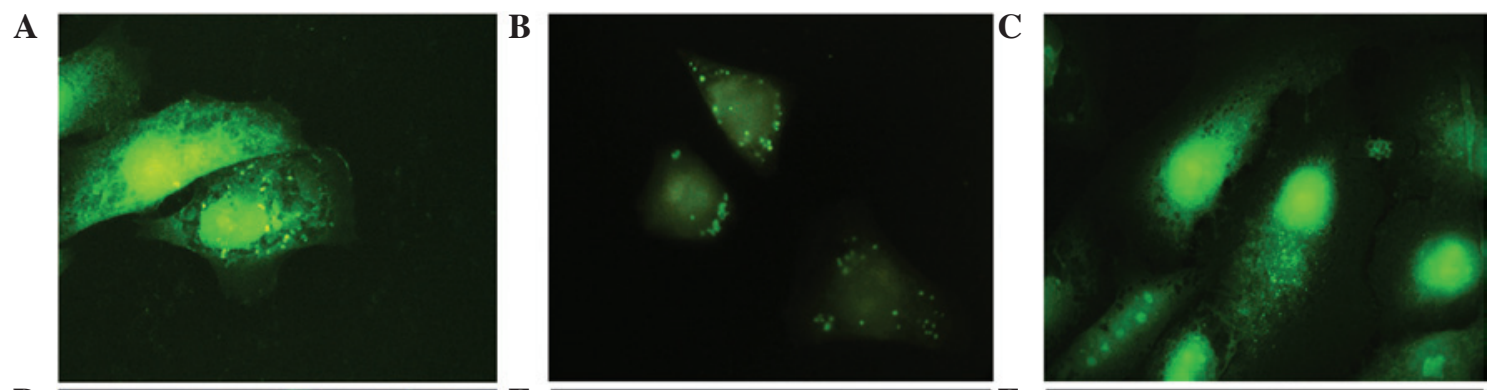

D
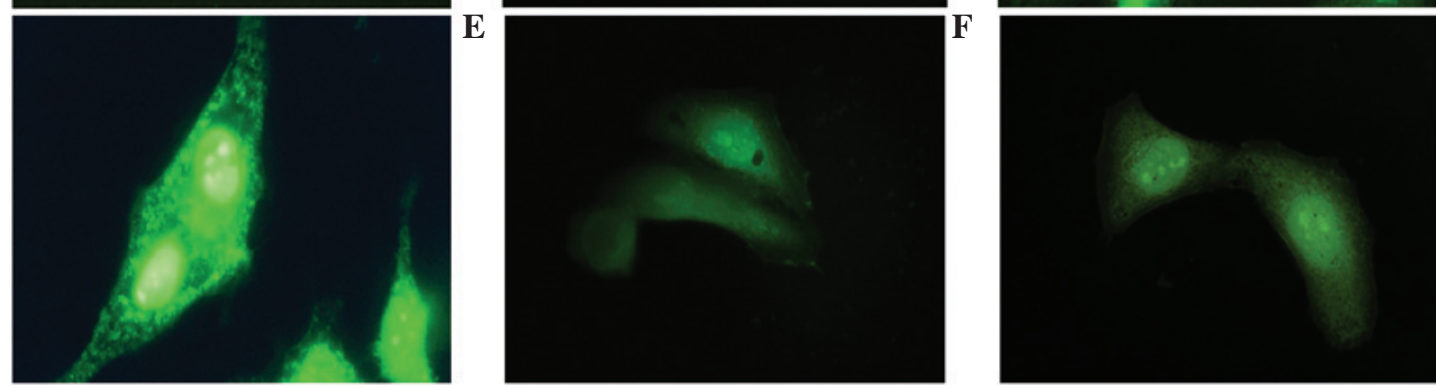

Figure 2. Immunostaining demonstrating $\beta 1$-integrin and FAK expression in HEp- 2 cells $12 \mathrm{~h}$ following PDT. The expression of $\beta 1$-integrin in (A) the control group, cells with labeled in border (arrow); (B) the $\mathrm{AlPcS}_{4} / \mathrm{PDT}$ group, cells with diffuse labeling in the cytoplasm (arrow); (C) the ZnPc/PDT group, cells with some diffuse labeling in cytoplasm (arrow). FAC expression in (D) the control group, with numerous focal adhesion points (arrow); (E and F) the AlPcS 4 /PDT and $\mathrm{ZnPc} / \mathrm{PDT}$ groups, where focal adhesion was not observed. PDT, photodynamic therapy; $\mathrm{AlPcS}_{4}$, aluminum phthalocyanine tetrasulfonated; ZnPc, zinc phthalocyanine; FAK, focal adhesion kinase.

cells were labeled for these adhesive proteins, but after $12 \mathrm{~h}$ occur a reduction of the same, when compared with the control group.

Effect of PDT on adhesion protein expression. The results observed in the immunostaining were confirmed by the analysis of the protein expression of FAK and $\beta 1$-integrin following PDT. The expression of the adhesion proteins FAK and $\beta 1$-integrin following PDT was assessed by RT-PCR. The analysis of the $\beta 1$-integrin mRNA expression in the $\mathrm{AlPcS}_{4}$ and $\mathrm{ZnPc}$ groups compared with the control group revealed no significant differences at the baseline time $(0 \mathrm{~h}$; Fig. 3$)$. However, $12 \mathrm{~h}$ following PDT, a significant reduction in the expression of $\beta 1$-integrin in the $\mathrm{ZnPc}$ and $\mathrm{AlPcS}_{4}$ groups, as compared with the controls, was observed. The expression of FAK mRNA in the two groups did not demonstrate a significant reduction when compared with the control group at $0 \mathrm{~h}$. By contrast, $12 \mathrm{~h}$ following PDT there was a significant reduction in the FAK mRNA expression in the $\mathrm{ZnPc}$ and $\mathrm{AlPcS}_{4}$ groups, when compared with the control group. Therefore, the two photosensitizers used demonstrated efficacy in reducing the expression of $\beta 1$-integrin and FAK, influencing the accession process following PDT.

Effect of PDT on cell-cell adhesion. To study cell-cell interactions, calcein-AM was used as an indicator of cell viability. The control and treatment groups were incubated with calcein-AM and cocultured in HEp-2 monolayer cells. The cells were incubated for 6, 12, 24 and $48 \mathrm{~h}$ to evaluate the adhesion ability following treatment with PDT. The behavior of the laser and control groups at all times demonstrated an increase in cell adhesion throughout the period analyzed. Cultures submitted to photodynamic treatment after 6,12, 24 and $48 \mathrm{~h}$ (Fig. 4) exhibited a marked reduction in the number of cells adhered to monolayer compared with the cells in the control group. In the $\mathrm{ZnPc}$ PDT group, the adherence rates were low at $6 \mathrm{~h}$, but demonstrated no significant change until $24 \mathrm{~h}$, with a significant

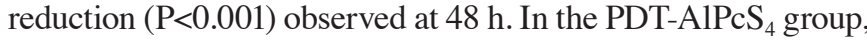
$<100$ cells were attached in the same period.

Effect of PDT on cell adhesion to the matrix. The capacity of cells to adhere to matrix, was evaluated using a colorimetric 

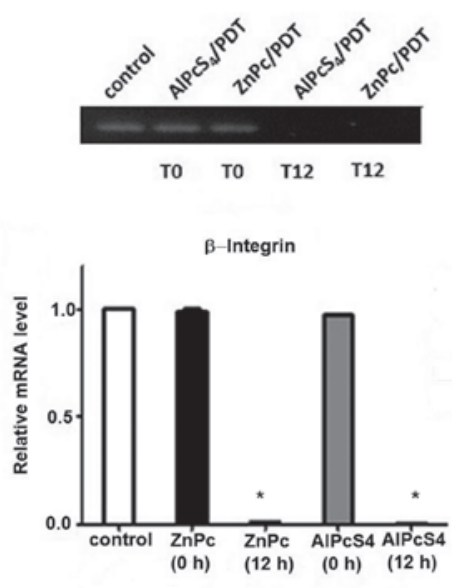

Photodynamic Therapy

B
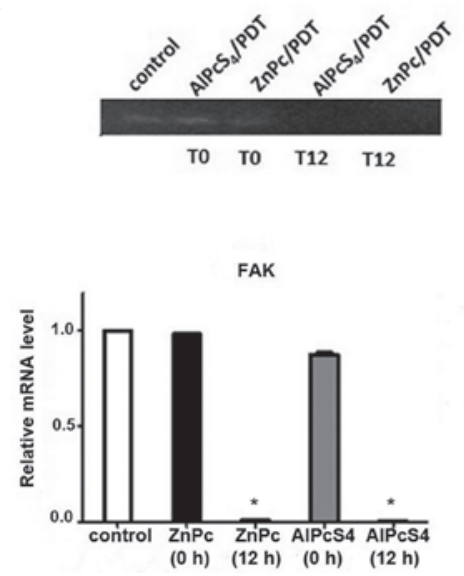

Figure 3. Effect of PDT on the mRNA expression of adhesion proteins. (A) There was no significant reduction in the mRNA expression of $\beta 1$-integrin in the two groups when compared with the control group at $0 \mathrm{~h}$. Following $12 \mathrm{~h}$ from PDT, there was a significant reduction in the expression in the $\mathrm{ZnPc}$ and $\mathrm{AlPcS}_{4}$ groups, when compared with the control group. (B) There was no significant difference in the expression of FAK mRNA for the two groups when compared with the control group at $0 \mathrm{~h}$. By contrast, $12 \mathrm{~h}$ following PDT, a significant reduction in the expression of FAK was observed in the $\mathrm{ZnPc}$ and $\mathrm{AlPcS}_{4}$ groups when compared with the control group. PDT, photodynamic therapy; $\mathrm{AlPcS}_{4}$, aluminum phthalocyanine tetrasulfonated; $\mathrm{ZnPc}$, zinc phthalocyanine; FAK, focal adhesion kinase.

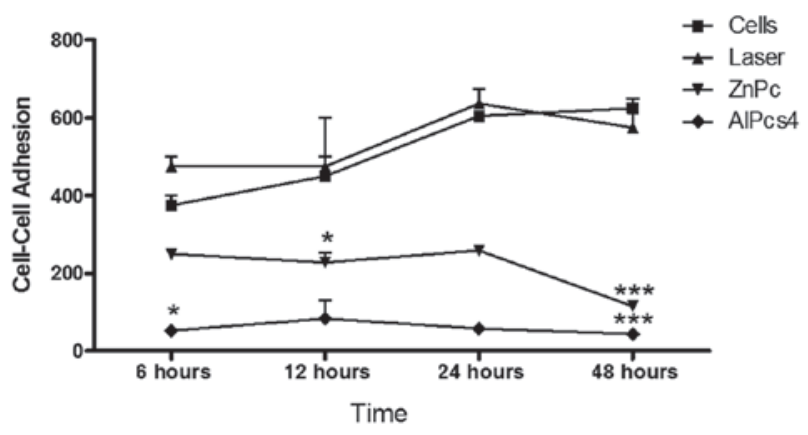

Figure 4. Cell-cell adhesion assay. Following PDT, the cells were incubated for periods of 6, 12, 24 and $48 \mathrm{~h}$. At the end of these periods the cultures were analyzed by fluorescence microscopy, counting the number of cells adhered to the monolayer. After $24 \mathrm{~h}$, the difference in the adhesion ability in the treatment groups, compared with the control, was significant $\left.{ }^{* * *} \mathrm{P}<0.001\right)$. When comparing the photosensitizers $\mathrm{ZnPc}$ and $\mathrm{AlPcS}_{4}$, there was no significant difference. PDT, photodynamic therapy; $\mathrm{AlPcS}_{4}$, aluminum phthalocyanine tetrasulfonated; $\mathrm{ZnPc}$, zinc phthalocyanine.

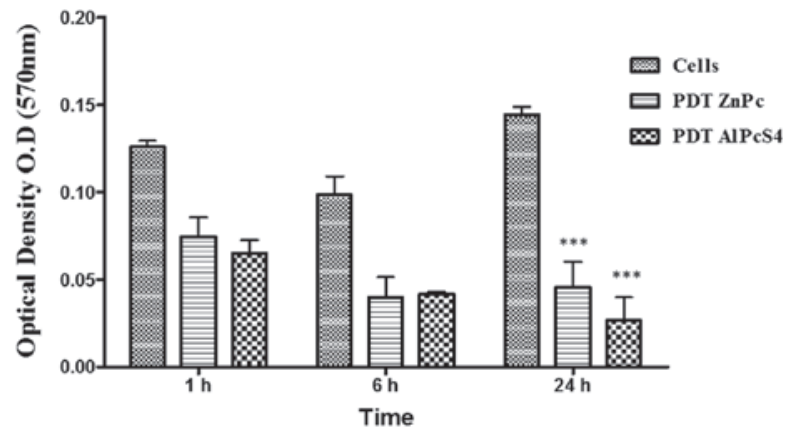

Figure 5. Cell-matrix adhesion assay. Following PDT, the cultures were incubated in collagen matrix IV at 1,6 and $24 \mathrm{~h}$, and analyzed by a colorimetric assay with crystal violet. In the $\mathrm{ZnPc} / \mathrm{PDT}$ group, the adherence rates initially (6 h) were low, but not significantly different from the control group $\left({ }^{*} \mathrm{P}>0.05\right)$. Following $12 \mathrm{~h}$, a significant reduction was observed $(\mathrm{P}<0.05)$ and from $24 \mathrm{~h}$ the reduction was significant compared with the control group $\left({ }^{* * * *} \mathrm{P}<0.001\right)$. PDT, photodynamic therapy; $\mathrm{AlPcS}_{4}$, aluminum phthalocyanine tetrasulfonated; $\mathrm{ZnPc}$, zinc phthalocyanine.

assay. Comparing the $\mathrm{ZnPc} / \mathrm{PDT}$ and $\mathrm{AlPcS}_{4} / \mathrm{PDT}$ groups with the controls, there was a significant reduction in the number of cells adhered $(\mathrm{P}<0.01)$ at the 1 and $6 \mathrm{~h}$ time points following incubation of the cells with the matrix. After $24 \mathrm{~h}$, this difference was significant $(\mathrm{P}<0.001)$. There was no significant difference in cell adhesion when comparing the two photosensitizers $\mathrm{ZnPc}$ and $\mathrm{AlPcS}_{4}$ (Fig. 5).

\section{Discussion}

The present study describes the effect of photosensitizers $\mathrm{ALPcS}_{4}$ and $\mathrm{ZnPc}$ on cell adhesion. AlPcS4 was found to modify the structure of actin filaments, with more severe changes identified during the periods of 12,24 and $48 \mathrm{~h}$, as demonstrated by labeling with phalloidin-TRITC. In cultures treated with $\mathrm{ZnPc} / \mathrm{PDT}$, it was possible to observe the presence of small cytoplasmic projections, with concentrated actin filaments in the cell edge, demonstrating that cellular organization was affected by PDT treatment following $12 \mathrm{~h}$, with a marginal recovery at $48 \mathrm{~h}$. The cellular structure of actin is recognized as crucial to the maintenance of cell adhesion, and is therefore one of the targets of PDT $(13,14)$; however, changes induced by PDT in the cytoskeletal proteins may be present in cells resistant to treatment, leading to changes in the adhesion and organization of the cytoskeletal components favoring the migration of these cells to other tissues. This alteration may be explained by the involvement of adhesion proteins, mainly $\beta 1$-integrin and FAK, as these proteins are dependent on the disposition of the actin filaments. In the present study, the immunostaining of $\beta 1$-integrin and FAK demonstrated a reduction in their protein expression $12 \mathrm{~h}$ following PDT. The RT-PCR results confirmed the reduction of the mRNA expression $\beta 1$-integrin and FAK, $12 \mathrm{~h}$ following PDT for the two photosensitizers. These results were corroborated in the study by Milla Sanabria et al (6), which suggested that the adhesion of the cell to the substratum is mediated by integrins, and would therefore be interrupted following photodynamic action by damage to the ECM and by damage directly to the integrin proteins.

The stability of integrin ( $\alpha$ and $\beta$ ) and FAK is dependent on the interaction with other proteins, such as vinculin, paxillin 
and actin filaments. In the present study, it was verified that the mRNA expression for adhesion proteins was reduced following PDT. This result indicates that PDT is not only acting to destabilize the interaction between the proteins involved in cell-substrate adhesion, as observed in the results of the cell-matrix interaction, but that it is also acting on signaling pathways in cells. The data of the violet crystal assay demonstrated a significant reduction in cell-matrix adhesion $24 \mathrm{~h}$ following PDT for the two phthalocyanines. This effect was also observed in cell-cell interactions in which a reduction of adhesion was observed following PDT, which was enhanced as the time increased. These results confirm earlier evidence from Runnels et al 1999 (15), who performed a similar study assessing the adhesion to collagen IV, laminin, fibronectin and vitronectin (components of ECM) with PDT-AlPcS4. The reduction of cell adhesion OVCAR 3 (human ovarian carcinoma) subjected to treatment with BPD-MA was attributed to the high rate of cell death observed in culture; however, even with decreasing rates of $\beta 1$-integrin in the focal adhesion plaques, there were no differences in the expression of this protein.

In conclusion, the phthalocyanines $\mathrm{AlPcS}_{4}$ and $\mathrm{ZnPc}$, following irradiation, induce damage that compromises the cell adhesion ability and inhibits the metastatic potential of HEp-2 cells. However, further studies are required to determine the signaling pathways involved in the resistance of the surviving cells.

\section{Acknowledgements}

A grant support for this study was provided by Fundação de Amparo à Pesquisa do Estado de São Paulo-FAPESP no. 2006/06736-5.

\section{References}

1. Juarranz A, Espada J, Stockert JC, et al: Photodamage induced by Zinc(II)- phthalocyanine to microtubules, actin, alpha-actinin and keratin of HeLa cells. Photochem Photobiol 73: 283-289, 2001.
2. Dolmans DE, Fukumura D and Jain RK: Photodynamic therapy for cancer. Nat Rev Cancer 3: 380-387, 2003.

3. Allison RR and Moghissi K: Photodynamic Therapy (PDT): PDT Mechanisms. Clin Endosc 46: 24-29, 2013.

4. Dougherty TJ, Gomer CJ, Henderson BW, et al: Photodynamic therapy. J Natl Cancer Inst 90: 889-905, 1998.

5. Castano AP, Demidova TN and Hamblin MR: Mechanisms in photodynamic therapy: Part three-Photosensitizer pharmacokinetics, biodistribution, tumor localization and modes of tumor destruction. Photodiagn Photodyn Ther 2: 91-106, 2005.

6. Milla Sanabria L, Rodríguez ME, Cogno IS, et al: Direct and indirect photodynamic therapy effects on the cellular and molecular components of the tumor microenvironment. Biochim Biophys Acta 1835: 36-45, 2013.

7. Pazos MD and Nader HB: Effect of photodynamic therapy on the extracellular matrix and associated components. Braz J Med Biol Res 40: 1025-1035, 2007.

8. Uzdensky A, Kolpakova E, Juzeniene A, Juzenas P and Moan J: The effect of sublethal ALA-PDT on the cytoskeleton and adhesion of cultured human cancer cells. Biochim Biophys Acta 1722: 43-50, 2005.

9. Ferreira SDRM, Tedesco AC, Sousa G, et al: Analysis of mitochondria, endoplasmic reticulum and actin filaments after PDT with AlPcS(4). Lasers Med Sci 18: 207-212, 2004.

10. Tsai T, Ji HT, Chiang PC, Chou RH, et al: ALA-PDT results in phenotypic changes and decreased cellular invasion in surviving cancer cells. Lasers Surg Med 41: 305-315, 2009.

11. Machado AH, Moraes KC, Pacheco-Soares C, et al: Cellular changes after photodynamic therapy on HEp-2 cells using the new $\mathrm{ZnPcBr}(8)$ phthalocyanine. Photomed Laser Surg 28 (Suppl 1): S143-S149, 2010.

12. Milla LN, Cogno IS, Rodríguez ME, Sanz-Rodríguez F, Zammarrón A, Gilaberte Y, Carrasco E, Rivarola V and Juarranz A: Isolation and characterization of squamous carcinoma cells resistant to photodynamic therapy. J Cell Biochem 112: 2266-2278, 2011.

13. Liu T, Wu LY and Berkman CE: Prostate-specific membrane antigen-targeted photodynamic therapy induces rapid cytoskeletal disruption. Cancer Lett 296: 106-112, 2010

14. Casas A, Sanz-Rodriguez F, Di Venosa G, et al: Disorganisation of cytoskeleton in cells resistant to photodynamic treatment with decreased metastatic phenotype. Cancer Lett 270: 56-65, 2008.

15. Runnels JM, Chen N, Ortel B, et al: BPD-MA-mediated photosensitization in vitro and in vivo: cellular adhesion and betal integrin expression in ovarian cancer cells. Br J Cancer 80: 946-953, 1999. 